\title{
Specific Induced Activity Profile at the Rotary Specimen Rack of IPR-R1 TRIGA Reactor
}

\author{
Dante Marco Zangirolami ${ }^{1,2 *}$ and Andréa Vidal Ferreira ${ }^{\dagger}$ \\ ${ }^{1}$ National Committee of Nuclear Energy - CNEN, Nuclear Technology Development Center - CDTN, \\ Av. Presidente Antônio Carlos, 6627 - Campus UFMG 31270-901 Belo Horizonte, MG, Brazil \\ Arno Heeren de Oliveira \\ ${ }^{2}$ Department of Nuclear Engineering Federal University of Minas Gerais State, \\ Av. Antônio Carlos, 6627 - Campus UFMG, 31.270-090 Belo Horizonte, MG, Brazil
}

(Received on 16 June, 2008)

\begin{abstract}
The IPR-R1 TRIGA nuclear reactor at Nuclear Technology Development Center, CDTN/CNEN, Belo Horizonte, Brazil, has a rotary specimen rack, RSR, outside the reactor core, and it is composed for forty irradiation channels in a cylindrical geometry. The aim of this work is to evaluate the neutron fluence rate distribution at the RSR and its variation under different irradiation conditions by means of specific induced activity measurements. Al-0.1\% Au reference materials were irradiated simultaneously at $100 \mathrm{~kW}$ in these irradiation channels and gamma spectrometry was applied with HPGe detector to determine the specific induced activity. This procedure was repeated six times. The results show an asymmetrical neutron fluence rate distribution at the RSR. The variation between the minimum and the maximum specific induced activity values in the RSR channels is about $14 \%$.
\end{abstract}

Keywords: TRIGA nuclear reactor, neutron fluence rate, neutron activation

\section{INTRODUCTION}

The IPR-R1 TRIGA MARK 1 nuclear reactor of CDTN/CNEN in the city of Belo Horizonte, Brazil, has been operating since 1960. TRIGA utilizes solid fuel elements in which the zirconium-hydride moderator is homogeneously combined with $20 \%$-enriched uranium. It uses graphite as reflector and deionized light water as moderator and cooling. IPR-R1 is used in neutron physics research, production of radioisotopes for industrial, medical and environmental applications, besides sample irradiation for instrumental neutron activation analysis INAA. It has three facilities for sample irradiation: the central thimble $\mathrm{CT}$, the rotary specimen rack RSR and the pneumatic tube transfer system PT. The power level of the reactor is controlled with three control rods: Regulating, Shim, and Safety. The actual reactor core configuration has 63 fuel elements, as shown in Figure 1. The CT is placed at the center of core reactor and permits sample irradiation with maximum neutron fluence rate, besides neutron beam extraction. This facility is made of anodized aluminum tube with an external diameter of $3.81 \mathrm{~cm}$, an internal diameter of $3.38 \mathrm{~cm}$ and $6.1 \mathrm{~m}$ height. CT is removable and when it is not in use the reactor pool water occupies its volume. The PT facility is mainly used for analysis by the delayed fission neutron method. The RSR is placed outside the reactor core and has 40 irradiation channels, each one with $31.75 \mathrm{~mm}$ diameter and $27.4 \mathrm{~cm}$ high for sample accommodation. RSR is the most used irradiation facility at IPR-R1, which has the INAA as one of the main applications [1 - 8]. Actually sample irradiations for INAA at RSR are made with this facility unmoving due to the aging of the rotary mechanism. Previous measurements $[4,6]$ indicate significant variation of the neutron fluence rate distribution between the RSR irradiation

\footnotetext{
*Electronic address: dmz@cdtn.br

${ }^{\dagger}$ Electronic address: avfecdtn.br

¥Electronic address: arno.heeren@pesquisador.cnpq.br
}

channels.

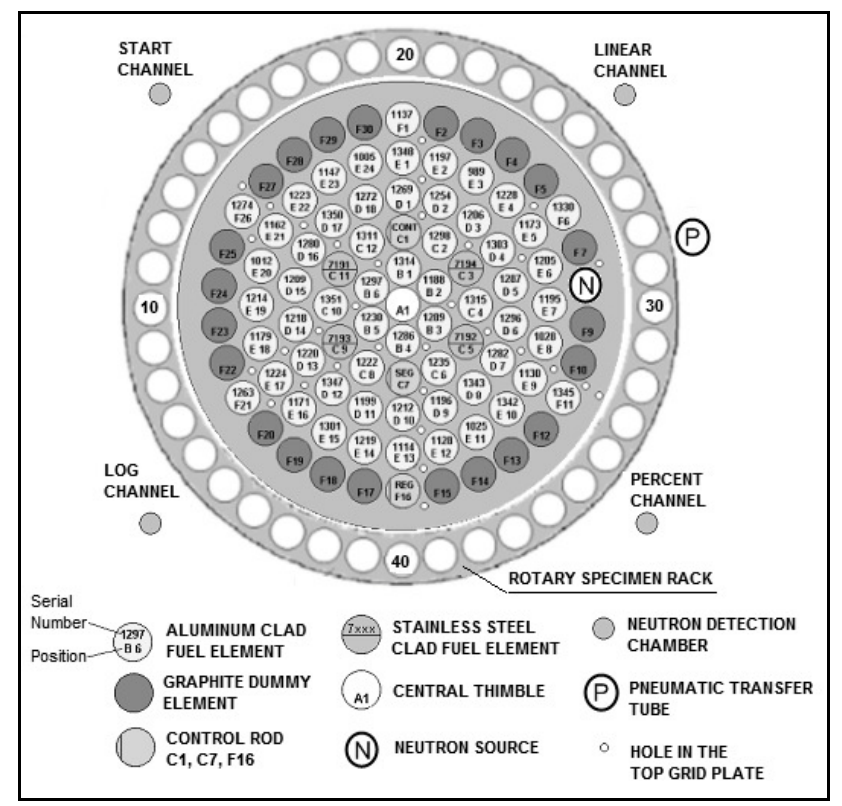

FIG. 1: Actual horizontal cross-section of IPR-R1 TRIGA Mark I reactor core [9]

The aim of this work is to evaluate the neutron fluence rate distribution at $100 \mathrm{~kW}$ in the RSR and its variation under different irradiation conditions by means of specific induced activity measurements.

\section{MATERIALS AND METHODS}

\section{II.1. Experiment}

Al-0.1\% Au reference material [10] was used as neutron fluence rate detector. The reference material was cut in disks about $1 \mathrm{~cm}$ diameter and weighted in a precision balance. A 
set of 39 disks was irradiated simultaneously in 39 irradiation channels of the rotary specimen rack. The channel 4 (showed in Figure 1) of the RSR is not in use at this moment. During the irradiation, the rotary specimen rack remained unmoving. The irradiations were performed in six different dates between 4 Mach, 2008 and 29 April, 2008. For each date, it was applied the same irradiation time, 1 hour, and the same reactor power, $100 \mathrm{~kW}$. In these six irradiations, the operational conditions were chosen to simulate the typical conditions of reactor operation. On this purpose, sometimes bared or $\mathrm{Cd}$ covered samples were introduced into the CT. Besides, sometimes CT was removed from the reactor core. Table 1 resumes the operational conditions of the six experiments. The column Reactor Status indicates the previous utilization of the IPR-R1: "cold" means at least five days of reactor inactivity, and "hot" means at least eight hours of reactor operation at the day before the experiment.

After the irradiation, the samples were removed from the RSR and two days later they were submitted to gamma spectrometry. The gamma spectrometer system is equipped with an HPGe detector model CANBERRA ${ }^{\circledR} 5019$ (counting efficiency: 50\%; resolution: FWHM $1,85 \mathrm{keV}$ for $1332 \mathrm{keV}$ gamma energy from 60Co), and the software Gennie 2000 v2.0, CANBERRA ${ }^{\circledR}$. The counting time was adjusted to provide a net peak area about 60,000 counting for the 411.8keV peak from 198Au radioisotope.

\section{II.2. Theoretical basis:}

The characteristic nuclear reactions in the experiment are:

$$
\begin{aligned}
& { }^{197} A u(n, \gamma){ }^{198} A u \\
& { }^{27} A l(n, \gamma){ }^{28} A l
\end{aligned}
$$

The ${ }^{198} A u$ radioisotope has a half-life of 2.694 days, and the ${ }^{28} \mathrm{Al}$ radioisotope has a half-life of 2.24 minutes. Therefore, after half an hour, almost all ${ }^{28} \mathrm{Al}$ have been decayed, not disturbing the ${ }^{198} A u$ counting, which was performed two days after the irradiation.
The reaction rate per nucleus, $R$, of the formed radioisotope is given by [11]:

$$
R=\int_{0}^{\infty} \sigma(E) \phi(E) d E
$$

where $E$ is the neutron energy in $\mathrm{eV} ; \sigma(E)$ is $(\mathrm{n}, \gamma)$ crosssection of target nuclei in $\mathrm{cm}^{2} ; \phi(E)$ is the neutron fluence rate per unit of energy interval in $\mathrm{cm}^{-2} \cdot \mathrm{s}^{-1} \cdot \mathrm{eV}^{-1}$.

Adopting the Hogdahl convention [11]:

$$
R=\left(\phi_{t h} \sigma_{t h}+\phi_{e p i} I_{\gamma}\right)
$$

where $\sigma_{t h}$ is the thermal neutron radioactive capture crosssection of the target nuclei; $\phi_{t h}$ and $\phi_{\text {epi }}$ are the thermal and epithermal neutron fluence rates, respectively, in sample channel; and $I \gamma$ is the radioactive capture resonance integral of the target nuclei.

The sample induced activity $A_{0}$ at the end of the irradiation time $t_{i r r}$, is given by [11]:

$$
A_{0}=N\left(\phi_{t h} \sigma_{t h}+\phi_{e p i} I_{\gamma}\right)\left(1-e^{-\lambda t_{i r r}}\right)
$$

where $N$ is the number of target nuclei in the sample; $\lambda$ is the radioisotope decay constant $\left(\lambda=\ln 2 / T_{1 / 2} ; T_{1 / 2}\right.$ is the radioisotope half-life).

After gamma spectrometry analysis, the specific induced activity may be obtained by [11]:

$$
A_{0}=\frac{N_{p} e^{\lambda t_{d}}}{\varepsilon \gamma \theta w t_{m}}
$$

where $t_{d}$ is the time interval between the irradiation ending and start counting; $t_{m}$ is the counting interval time; $\varepsilon$ is photo peak counting efficiency; $\theta$ is isotopic abundance of the target nuclide; $\gamma$ is the gamma emission probability; $w$ is the target nuclide mass in the sample; $N p$ is the counts number of the photo peak, in interval $t_{m}$.

The uncertainty analysis based on Equation 6 leads to:

$$
\frac{\sigma_{A_{0}}}{A_{0}}=\sqrt{\frac{\sigma_{N_{p}}^{2}}{N_{p}^{2}}+\frac{\sigma_{W}{ }^{2}}{w^{2}}+\frac{\sigma_{\varepsilon}^{2}}{\varepsilon^{2}}+\frac{\sigma_{\gamma}^{2}}{\gamma^{2}}+\frac{\sigma_{\theta}^{2}}{\theta^{2}}+\frac{\sigma_{t_{m}}^{2}}{t_{m}^{2}}+\left(t_{d} \sigma_{t_{d}}\right)^{2}+\left(\lambda \sigma_{\lambda}\right)^{2}}
$$

In the Equation $7, \theta, t_{m}, t_{d}, \gamma$, and $\lambda$ uncertainties are very small and therefore the last five terms are negligible. Then,

$$
\frac{\sigma_{A_{0}}}{A_{0}} \cong \sqrt{\frac{\sigma_{N p}^{2}}{N_{p}^{2}}+\frac{\sigma_{w}^{2}}{w^{2}}+\frac{\sigma_{\varepsilon}^{2}}{\varepsilon^{2}}}
$$

\section{RESULTS AND DISCUSSIONS}

Figure 2 presents the specific induced activity results obtained for all the RSR channels. The channel 4 results are the mean values of data from channel 3 and channel 5. In Figure $2 \mathrm{~A}$, the results for all the six experiments are presented. In these experiments, typical uncertainty values (equation 8 ) are: $\sigma_{N p} / N_{p}=0.007 ; \sigma_{w} / w=0.004 ; \sigma_{\varepsilon} / \varepsilon=0.02 ;$ which leads to $\sigma_{A o} / A_{o}=0.02$. The error bars representing uncer- 
Table 1 - IPR-R1 Operational Conditions

\begin{tabular}{cccc}
\hline EXPERIMENT & SAMPLE IN RSR & SAMPLE IN CT & REACTOR STATUS \\
\hline 1 & B & CT absent & hot \\
2 & B & CT absent & hot \\
3 & B & CT absent & hot \\
4 & B & CT absent & cold \\
5 & B & B & hot \\
6 & B & Cd & cold \\
\hline
\end{tabular}

$\mathrm{B}=$ Bared $\quad \mathrm{Cd}=$ Cadmium covered

tainty values were omitted in Figure 2A. Figure 2B shows the mean value and standard deviation (bar error) of specific induced activity in each RSR channel.

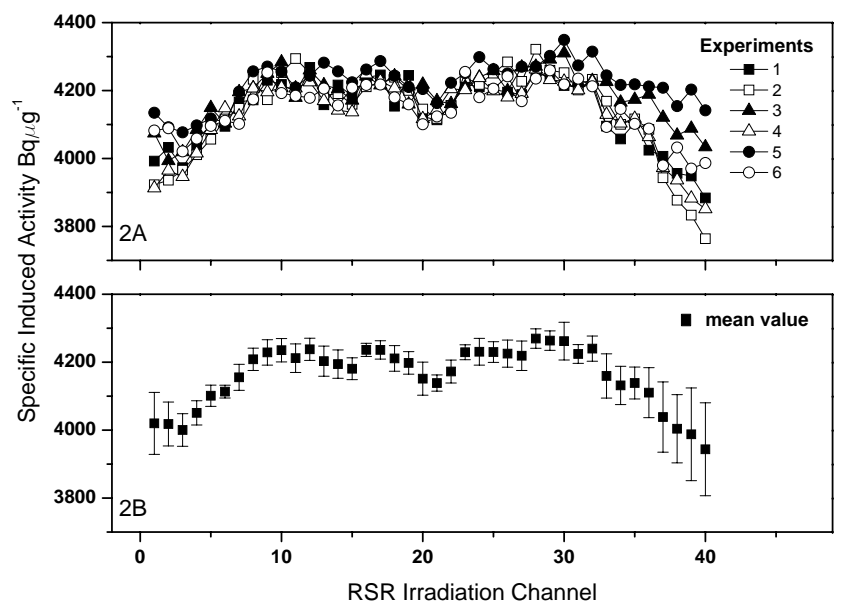

FIG. 2: Specific induced activity for the Reference Material

Figure 2B shows that from channel 1 to channel 10 the mean value of the specific induced activity in each channel tends to increase. This fact may be explained by the reactor core configuration (Figure 1). The F16 core reactor position is occupied the REGULATING control rod. The control rods, neutron absorbers, disturb the neutron fluence rate in their vicinity. From channel 1 to channel 10, the distance from the
REGULATING control rod increases. This explains the increase of the observed specific induced activity in this region. Figure 2B also shows that the mean value of the specific induced activity tends to decrease from channel 30 to 40 . Due to the cylindrical core configuration, this observation also may be explained by the relative position of these channels to the REGULATING control rod.

The specific induced activity values in the RSR show a relatively flat maximum from the 10 to the 30 channels. This fact is also explained by the reactor core configuration: these channels are far from the REGULATING control rod. The small observed specific induced activity depression around channel 20 may be explained by the SHIM control rod position ( $\mathrm{C} 1$ position in Figure 1). This control rod is placed on the axis passing through the tree control rods and the 20 channel.

Figure 2 shows that the greatest values of the specific induced activity standard deviation are from the channel 36 to 02. This fact is due to the neighborhood of the REGULATING rod position. In each experiment, the REGULATING control rod vertical position varies according to the reactor start up procedure, which is manual.

In order to illustrate the behavior of channels 36 to 02 , Table 2 presents the data about REGULATING and SHIM control rods vertical positions and the specific induced activity in the channel 40. In all reactor operation the SAFETY control rod (labeled C7 in Figure 1) is withdrawn from the core.

Table 2 - Experiments Summary - IPR-R1 at 100kW

\begin{tabular}{|l|l|l|l|l|}
\hline $\begin{array}{l}\text { Experiment } \\
\text { number }\end{array}$ & $\begin{array}{l}\text { REGULATING } \\
\text { rod position* }\end{array}$ & $\begin{array}{l}\text { SHIM rod posi- } \\
\text { tion* }\end{array}$ & $\begin{array}{l}\text { Specific Induced } \\
\text { Activity in channel } \\
\mathbf{4 0}\left(\mathbf{B q} \cdot \mu^{-1}\right)\end{array}$ & $\begin{array}{l}\text { RSR Mean Specific In- } \\
\text { duced Activity and Stan- } \\
\text { dard Deviation }\left(\mathbf{B q} \cdot \mu \mathbf{g}^{-1}\right)\end{array}$ \\
\hline 2 & 560 & 570 & 3764 & $4132 \pm 136$ \\
\hline 4 & 588 & 595 & 3851 & $4132 \pm 111$ \\
\hline 1 & 642 & 580 & 3884 & $4134 \pm 102$ \\
\hline 3 & 693 & 580 & 4033 & $4184 \pm 77$ \\
\hline 6 & 694 & 609 & 3987 & $4146 \pm 79$ \\
\hline 5 & 830 & 605 & 4142 & $4221 \pm 65$ \\
\hline ALL & - & - & - & $4158 \pm 103$ \\
\hline
\end{tabular}


at channel 40: as more inserted the REGULATION rod is into the reactor core as lower is the specific induced activity at channel 40 . However, the RSR mean value of specific induced activity does not varies significantly with the REGULATION rod vertical position. This fact causes an increase in the value of standard deviation for RSR mean specific induced activity.

Tables 1 and 2 show that the CT presence, with or without Cd sample, has no significant influence in the neutron fluence rate in the RSR. In the same way, the reactor status (cold or hot) did not affect the experiments. The ${ }^{135} \mathrm{Xe}$ is a fission product, which absorbs neutrons. This effect is calling " ${ }^{135} \mathrm{Xe}$ poisoning". Hot reactor tends to have more of this element [12]. However, in our experiments, the reactor status has no significant influence in the neutron fluence rate in the RSR.

\section{CONCLUSIONS}

The results obtained indicate that the profile of the specific induced activity in the rotary specimen rack depends mainly on the control rods position during reactor criticality. For each experiment (one hour irradiation, $100 \mathrm{~kW}$ power) the specific induced activity value depends on the relative position between the RSR irradiation channel and the SHIM and the REGULATING control rods placement. Because of this it is possible to identify regions at RSR with similar variability.
One region at channels 36 to 02 with lower nominal neutron fluence rate and greatest standard deviation values. Another region from channels 10 to 30 with the greatest nominal values and lower standard deviations, presenting a small neutron fluence rate depression around channel 20. The reactor core has a symmetrical axis through control rods, but the specific induced activity profile does not match this axis, probably due to different fuel elements burning. The presence or absence of the CT facility, with or without samples does not cause significant neutron fluence rate variation at the RSR, and neither the reactor status (cold or hot).

Channel 40 has the lower specific induced activity mean value; the maximum values are around channels 10 and 30 . Channels 7 and 33 correspond to the RSR mean value. The variation between the minimum and the maximum specific induced activity values for the reference material is about $14 \%$.

\section{ACKNOWLEDGMENTS}

The authors would like to thank Dr. Amir Z. Mesquita, M.Sc Fausto M. Júnior, Supervisors of the IPR-R1 TRIGA reactor and to Reactor Operators Paulo F. Oliveira and Luiz O. I. S. Câmara. We are grateful to M.Sc Geraldo F. Kastner, Dr. Rose M. G. P. Souza and Dr. Maria Â. B. C. Menezes for their help and support.
[1] M. A. R. V. Veado, G. Pinte, A. H. Oliveira, G. Revel, Journal of Radioanalytical and Nuclear Chemistry 217, 101 (1997).

[2] M. A. R. V. Veado, A. H. Oliveira, M. I. Severo, M. F. GrenierLoustalot, I. A. Arantes, H. L. Cabaleiro, M. R. M. G. Almeida, Journal of Radioanalytical and Nuclear Chemistry 272, 511 (2007).

[3] M. A. R. V. Veado, I. A. Arantes, A. H. Oliveira, M. R. M. G. Almeida, R. A. Miguel, M. I. Severo and H. L. Cabaleiro, Environmental Monitoring and Assessment 117, 157 (2006).

[4] M. Â. B. C. Menezes, R. Jacimovic, Nuclear Instruments \& Methods in Physics Research A 564, 707 (2006).

[5] M. Â. B. C. Menezes, C. V. S. Sabino, A. M. Amaral, E. C. P. Maia, Journal of Radioanalytical and Nuclear Chemistry 245, 173 (2000).

[6] D. M. Zangirolami, A. V. Ferreira, G. F. Kastner, R. M. G. Gontijo, A. M. Amaral, A. P. Alves, Proceedings of the VIII ENAN (SP, Brazil, 2007).

[7] M. Â. B. C. Menezes, C. V. S. Sabino, M. B. Franco, G. F.
Kastner, E. H. M. Rossi, Journal of Radioanalitical and Nuclear Chemistry 257, 627 (2003).

[8] A. Leal, M. Menezes, R. Rodrigues, O. Andonie, P. Vermaercke, L. Sneyers, Applied Radiation and Isotopes 66, 1307 (2008).

[9] A. Z. Mesquita: Investigação Experimental da Distribuição de Temperaturas no Reator Nuclear de Pesquisa TRIGA IPR-R1, Thesis, Faculdade de Engenharia Química de Campinas, Brazil (2005).

[10] Institute for Reference Materials and Measurements, Certified reference material IRMM-530R, Certificate of analysis, Gold mass fraction in Al-0.1\% Au Alloy. Geel, Belgium, 2007.

[11] F. de Corte, The k0-Standardization Method. A Move to the Optimization of Neutron Activation Analysis, Thesis, Gent University, Belgium (1987).

[12] A. Z. Mesquita, R. M. G Souza, Proceedings of the XV ENFIR (SP, Brazil, 2007). 